Article

\title{
S-s-s-syncopation: Music, Modernity, and the Performance of Stammering (Ca. 1860-1930)
}

\section{Josephine Hoegaerts}

Helsinki Collegium for Advanced Studies, University of Helsinki, Fabianinkatu 24, 00014 Helsinki, Finland; E-Mail: Josephine.hoegaerts@helsinki.fi; Tel.: +358-044-918-3213

Academic Editor: Megan Strickfaden

Received: 23 September 2015 / Accepted: 2 November 2015 / Published: 5 November 2015

\begin{abstract}
The modern history of disability, and of speech impediments in particular, has largely been written as one of medical discourse and (more recently) of social and cultural imaginations. The pathology of speech appears as an embodied, but ultimately intangible, issue due to the transient nature of sound itself. Once produced, it disappears, and seems to escape memory. In this text, stammering is approached as an object of material history. Drawing on the "paper trail" left by medical experts, popular entertainers and a handful of stammerers' experiences, this paper examines the ways in which stammering was made material in the nineteenth century. The impediment not only provided (pseudo) medical actors with a lucrative market for various curative objects and practices, but also propelled the (sheet-)music business. Stammerers themselves appear in this story of materialization and market as both agents and objects. The cheap self-cures, medical manuals, sheet music and (later) recordings that were produced not only for, but also by, them, show how easily the impediment was aligned with the modern consumer's identity and how the persona of the stammerer was, ultimately, lodged in the Western collective memory in very material ways.
\end{abstract}

Keywords: speech impediments; recording; music; history 


\section{Introduction}

En ik w-w-w-wil voor 'ulle

E 1-1-1-lieke zingen

Maar 'kwe-'kwe-'kweet nie

Hoe ' $\mathrm{k}$ m'n t-t-t-tong moet wringen.

(I want to sing a song for you,

But I don't know how to bend my tongue)

(“The Stammerer", recorded in Lier, Belgium, 1955)

On my laptop, there is a folder entitled "first family recording". It contains 46 MP3 files, the first of which reveals - after some initial spluttering and cracking - the very young and chirpy voice of my grandmother, announcing its date: November 1955. The rest of the folder preserves the voices of numerous family members, most of whom have now passed away, singing a song or reciting a poem. More than any photographs, these MP3s remind me of my family. Partly because their voices, the undeniable familiarity of the local dialect, and the cheekiness of their chosen material seems to "bring them to life" more than posed images, but also because I am familiar with the history of these files [1,2]. As the descendant of a mother, uncle, and grandfather with a mild obsession for audio-visual media, I grew up surrounded by the paraphernalia of recording technology_and I know that the "real" locus of my MP3s is a giant spool, tucked away in my parents' attic [3,4]. Somehow, my digital files seem fake, as imaginary as my memories of my singing family (which was recorded before even my mother was around). Most fascinating to me is the voice of my great-grandmother, whom I never knew. By all accounts she was a formidable woman, a stern and matronly widow, but on the recording she sings a drinking song, a very salacious ditty about a certain "Nicodemus", and the utterly silly stammering song cited above.

The song is clearly part of an oral tradition: the rhymes only work in the local dialect, and no written version seems to have existed. Through the recording, what would otherwise have been a completely transient piece of history has become fixed, and made material. With its stark ridicule of a speech impediment, it isn't a particularly nice song, either, but it fits with the sort of working-class culture one would expect in a small Belgian town in 1955. No doubt, no family gathering would have been complete without this type of song, an obligatory joke about a man with a wooden leg, and a couple of schoolchildren collecting tin foil (in Flemish known as "silver paper") for the poor "negroes" in Congo [5,6]. However, the fact that open expressions of ableism and racism were so widely accepted does not make songs like these insignificant. Their ubiquitous nature tells us a great deal about the history of popular perceptions of speech impediments, and material reminders (such as this recording) can alert historians to the very physical, performative ways in which perceptions of disability were passed on $[7,8]$. In "The stammerer", the singer takes on the role of the song's main character-thus literally embodying the impediment for his own and others' amusement. Intriguingly, it runs counter to the anecdotal, but very popular and often repeated information that stammerers can sing without struggle. Apparently, some people did stammer in song. Or maybe the singer's ability to stammer "at will" tells us something about his assumed vocal superiority. In any case, the stammerer is a figure to be laughed at and pitied: at the end of the song, he is rejected by his beloved because of his impediment. 
In this paper, I will focus my attention on the history of popular understandings of stammering and their relation to medical interpretations of speech impediments around the turn of the twentieth century. The material manifestations of stammering, an essentially immaterial and invisible phenomenon, will serve as the basis of my analysis. While recordings of local, patois songs are difficult to find, stammering songs (either as sheet music, or later as acoustic recordings) abound in the beginning of the twentieth century. The syncopated speech of the stammerer seemed particularly attractive to composers of syncopated music. As Daniel Goldmark has shown, the theme of stuttering was also of particular popularity in Tin Pan Alley music [9] (pp. 91-105). Likewise, the therapeutic methods of "stammering professors", whilst not tangible per se, have left a "paper trail" that allows us to reconstruct what discourses, methods, and objects were available to stammerers if they wanted to rid themselves of their affliction. I am thereby taking up Jonathan Sterne's suggestion in The Audible Past, who proposes that the "paper trail left by sound-reproduction technologies provides one useful starting point for a history of sound" [10]. The stammerer may have been depicted as the object of ridicule and pity, but he was also approached as an agent of his own cure, often by acting as a consumer of very specific material goods [11].

\section{The (Im)materiality of Stammering}

It may seem counterintuitive to look for materiality in stammering itself. After all, the stammer is first and foremost an acoustic phenomenon, a series of interrupted sounds and silences that can only exist as transient, fleeting moments [12,13]. Stammering can only occur during speech. Unlike the cane or wheelchair, or the "deficient" body parts of most people who are considered disabled, there does not seem to be a tangible locus for the stammerer's identity as the sufferer of an impediment. For 19th century observers, however, the voice in general and the stammering voice in particular seemed very material indeed. After ages of semi-religious interpretations of speech - notably equating the spoken word with the soul and the divine - the voice became firmly lodged in the throat by the end of the 18th century $[14,15]$. Experiments on dead larynxes showed that simply blowing air through the vocal tracts past the vocal chords could produce sounds, and the invention of mechanical devices such as Von Kempelen's "speaking machine" proved that the source of speech was material after all [16-19]. The 19th century, with its continuing attempts to employ machinery in understanding the mechanics of human speech, would become the age of the tangible and visible voice [20,21]. It would, in many ways, also become the age of the stammerer [22]. In their fervor to document the workings of the voice and understand its pathologies, physicians throughout Western Europe started to compile countless statistics on stammering as well. Weighing the percentages of male against female, young against old, poor against rich, and English against German or French stammerers, they looked for clues to find an explanation for an impediment that, they insisted, was bound to have a material presence within the stammerer's body [22] (pp. 31-41) and [23].

The insistence on the mechanical character of stammering reached its height in the first half of the 19th century, with surgeons such as Johan Friedrich Dieffenbach and James Yearsley inflicting bloody operations (and sometimes irreparable damage) on the tongues of stammerers [24-26]. Cutting the string of the tongue was nothing new - children who had trouble suckling were conventionally operated upon in this way-but its connection to fluent speech seemed tenuous, at best. Despite scathing criticism by other specialists, surgical treatment of a stammer became the hype in the 1840s. According to James 
Hunt, who became the stammering expert par excellence in the 1860 s and considered all operations on the tongue (an "innocent organ") useless, the "greatest zeal was exhibited in France" when it came to cutting tongues, and the "rage spread to America" very quickly [27] (pp. 112-114). Yet many seemed to think that the tongue - or the mouth in general — was at the root of all trouble. The first half of the 19th century spawned a broad range of mechanical remedies that would later be renounced as quackery. Harking back to the "classic" pebbles of Demosthenes, most were meant to almost literally bridle the tongue. "After an examination and comparison of the different methods of the educational treatment of stammering", it was claimed that:

"Every measure which has been advantageously employed may be reduced to a sort of obstacle or moderator, which is opposed to the irregular, abnormal, and embarrassed movements of the organs of speech. This moderator acts physically or materially; whether it be the pebbles employed by Demosthenes, the instrument for fixing the tongue, of M. Colombat, or the fork of M. Itard" (1841) [28].

The bride-langue played both on the increasingly "physical" scientific understanding of vocalization and on intuitive popular explanations of stammering (remember the stammerer who did not know how to "bend" his tongue in the song). Moreover, the reference to the pebbles of Demosthenes gave these methods a sheen of serious studiousness and appealed to a sort of collective (imagined) material memory. Anyone with a classic education would have heard of them, and their sheer physicality would have allowed stammerers to connect to the great "cured" orator on a very basic level.

The fads of the bride-langue and the tongue surgeries passed as quickly as they had risen. Although these mechanical devices, and the names of Itard, Yearsley, and Dieffenbach, would continually reappear in subsequent scientific work, they were mainly cited as reminders of the brutality and the simplistic stupidity of the recent past. Around 1860 - after the invention of the laryngoscope - the importance of the tongue and facial muscles in stammering was downplayed by all. Instead, both physicians and voice therapists claimed that the stammerer's body as a whole caused his hesitant speech. The cure, therefore, was not to loosen the tongue, but to train all parts of the body involved in speech: the muscles, lungs, and organs, as well as the "will". The approach was a holistic, but ultimately corporeal one: it focused on the flow of breath, an invisible but tangible and measurable process [29,30]. Additionally, at the basis of the mechanism were notions of morality. Stammering, it was believed, was the physical manifestation of moral imperfections. Therefore, a stammerer's cure would depend on the patient's physical and moral characteristics [31]. The weakness in the stammerer's speech betrayed a weak body molded by a lack of courage and steadfastness, and the stammerer was warned he would have to "stand face to face" with his impediment and "confront it like a man" [32] (p. 52). Gymnastic exercises would help him do so by creating a stronger, manlier, and more vigorous body.

Going from these moral explanations of stammering to the neurological and psychological interpretation of the impediment in the late 19th and early 20th centuries was but a small step. By the end of the century, the theories of Sigmund Freud had been applied to the issue of pathological speech: the stammerer was, according to therapists like Alfred Appelt, not cowardly at all. His fear of speech (or of particular words) could be considered a phobia. Behavioral therapy would free him from his fears, as well as his stammer: the "rational treatment" would "remove all psychic obstacles which separate the patient from his environment". Through this treatment, "all interferences with normal innervation of 
speech cease, and the sufferer can enjoy again unrestricted freedom of utterance" [33]. Despite its seeming immateriality, these theories had speech lodged in the body as well-more specifically, in the brain. In 1865 Paul Broca had suggested that speech could in fact be quite precisely located within the brain [34]. His theory had not been accepted by many at the time of publication, but by the end of the century, neurology was advancing rapidly and the "speech center" was identified as a site of possible pathologies. In less specialized works, authors represented the brain as a telephone exchange, where cross-wiring could play havoc with a person's ability to speak. According to American businessman and voice enthusiast Emil Sutro, for example:

"The brain is not the sole seat and custodian of the intellect and the mind. It is the central station, rather, as it were, of a net of telegraph or telephone wires, in which messages are received and from which messages are sent out in a thousand directions" (1904) [35].

These notions of the stammering brain absolved stammerers of moral shortcomings and made stammering identifiable again: the stammer could once more be located in a very particular part of the body.

It is no surprise, then, that the cures and objects presented to stammerers in the second half of the 19th century tended to be geared toward materiality as well. In many ways, turning the performative and immaterial character of stammering into a specific, tangible problem to be solved was the explicit goal of most therapeutic manuals, and even moreso of self-help books. The assertion that one could lose a stammer by grasping the legs of chair gave the purchaser of such brochures something to hold on to [32] (p. 147). Additionally, the manuals, tongue bridles, images, etc. marketed to stammerers had a physical presence of their own. By the end of the nineteenth century, stammering had become a business, with different therapists and methods fighting for clients' attention. The relatively famous Mr. Beasley advertised his method in the Bucks Herald in the 1860s, whilst in the Cheltenham Looker-On a stammerer could find an advertisement for "a LADY" giving "instruction in cases of stammering and defective articulation". In the Liverpool Daily Post a local headmaster who claimed to have extensive experience advertised the possibility of individual instruction. The cures targeted a middle-class audience that would presumably care most about speech impediments (they were in a profession requiring fluent speech), but — more importantly — would also have the means to afford a cure. Self-help manuals seem to have targeted a similar audience: they were relatively cheaply produced, but a book on stammering would necessarily have been a "luxury" item, requiring its owner to be literate [36-38]. This image of the consumer of self-help manuals dovetailed conveniently with the image of what most scientists considered to be the typical stammerer: a white middle-class man, the victim of the modern "strenuous" life, but also autonomous and capable of curing himself.

This "happy" collusion between consumerism and stammering is what allows us to study the history of stammering beyond scientific and popular discourses: studying the objects handled, purchased, and (sometimes) preserved by their original owners allows for a different perspective on stammering's past. It opens a space between individual, living memory, and the distant cold eye of history [39-41]. The "paper trail" left by stammering therapies can fulfill a role very similar to that of my "first family recording". Their tangibility can create imaginary memories - it is easy to imagine the person holding the manual, desperately trying to pronounce the odd series of prescribed sounds. Walter Yearsley's Practical Self-Cure of Stammering and Stuttering, for example, contained a sequence of syllables to be read rhythmically, "to one 'tick' or 'tack" of a metronome [32] (p. 145). The manuals are also "like" 
recordings in that they "represent performances through complex processes of cultural signification" [42]. Although these very particular, performative texts capture specific moments in time, they also refer to more widely held beliefs and more widely practiced performances. Picking up a stammering self-cure inscribed with its owner's name not only connects me to one particular stammerer in the past, but to a whole culture and all its unspoken norms and ideals pertaining to faultless speech.

\section{The Privilege of Stammering}

One clear indication of the lucrativeness of the business of speech therapy was the secretiveness of therapists about their own methods. Even the more "scientifically" inclined therapists were reluctant to give too much away in their publications. James Hunt was torn between the transparency necessary for the advancement of knowledge and the danger of putting specialists out of business by revealing too much of their methods. "We may", he noted, "in the abstract, admit that a person in full possession of a remedy tending to relieve any of the ills incidental to the human frame is morally bound to divulge it, and to look for a reward in his own conscience; even although a professional man's experience may be his stock in trade" [27] (p. 129). The great majority of "stammering professors" was even more secretive. The illustrious Malebouche's cure for stammering was only exposed when Dr. Magendie brought it to the attention of the French Academy of Science. Malebouche, in his turn, had purchased the method of a certain American: Mrs. Leigh. She was a very early example of the authority women were able to acquire in the fields of voice therapy and vocal education (Emma Seiler managed to make a name for herself as a scholar of the singing voice in the 1870s, and in the early 20th century women like Elsie Fogerty, Anne McAllister, and Winifred Kingdon Ward were instrumental in establishing speech therapy as a professional field). All beneficiaries of the "infallible method" of Mrs. Leigh were apparently sworn to secrecy - and hot speculation regarding the involvement of her landlord, Dr. Yates, in devising the method ensued. Central to the argumentation for all this secrecy was the performance-based nature of all the cures. Like stammering itself, the therapy for stammerers only existed "in practice". As Hunt stressed, it would be impossible to convey his methods on paper. "Simple of application as my system is in one case, it is intricate and complicated in another. But were it even possible to describe all the minutiae of a mode of treatment adapted to all imaginable cases, it would be useless, if not productive of mischief, unless the individual who applies it has qualified himself for the task by an extended practical experience" [27] (pp. 130-131).

This performative nature of stammering cures is precisely what makes the cheap booklets-which do contain some methods and practical hints - so interesting. Rather than a consistent narrative about stammering, or a linear development of a theory on the pathology and its cure, these booklets are an incitement to action. One method advised the reader to observe actors or particularly good orators in order to mimic their speech. Whereas that particular piece of advice seems vague (and rather obvious), his suggestion to sit in front of a mirror to copy fluid speech "precisely" is a much more concrete prescription, as well as more stringent. A clearly drawn picture showed just how one had to sit in front of the mirror while reading speech exercises in which every inhalation of breath was noted as well. Reading the advice, booklet in hand, it is almost impossible to resist the temptation to find a mirror and try it out. " $\uparrow$ Ancient customs of the Gauls $\rightarrow \rightarrow$. $\uparrow$ Wo - men were admitted into all the assemblies $\rightarrow \rightarrow \rightarrow$. $\uparrow$ whe - re questions of peace and war were debated $\rightarrow \longrightarrow \rightarrow$ " [43] (p. 256). Manuals of vocal 
therapies are full of these little moments of audience participation. The author asks the reader questions, encourages him to self-diagnose, and figures as the participant in an imaginary conversation with someone who could very well be the reader. This was a technique exhibited in Benjamin Beasley's work, for example. Beasley imagined a conversation in which he answered some "frequently asked questions" on stammering.

Can stammering be cured?

It can: for many years I held a different opinion.

Why so?

Because for many years I was an inveterate stammerer myself, and now I do not stammer.

Did you cure yourself?

Certainly.

How did you do so?

By first learning the cause, and then observing others who spoke well (1888) [44] (p. 39).

Walter Yearsley appeared as a stammerer in his own books as well, and included extracts from his own diary as proof of his experience of his self-cure.

"Tuesday". Had a successful day. Did not stammer once. Went into Mr. Lee's shop this morning and asked for something that I knew he did not keep! Provoked the assistant somewhat, by feigning annoyance because he did not keep the article. He unconsciously stammered out all sorts of excuses. I kept quite cool, and was tickled to think that I could so confuse a fluent speaker as to make him stammer in argument. This shopping business is excellent practice (1909) [32] (p. 94).

Appealing to the stammering consumer's will to act and take control of his impediment also accorded him some measure of agency. It is very easy to see the stammering professors, authors of self-help books, and cloak-and-dagger figures like Malebouche as quacks, preying on the insecurities of "victims" of an unfortunate impediment. They were, of course, by no means selfless, but neither did they treat their clients as gullible victims. In the process of attempting to "cure" stammerers (and making their purses a bit lighter), many of these authors also empowered the stammerer, and shored up his (almost exclusively) middle-class identity. The statistics compiled throughout the 19th century and random case studies proved particularly suitable for doing so. Stammerers, it was often claimed, were typically found in the professional classes and characterized by an extraordinary intelligence. "Children of weak intellect rarely stutter", according to Klindworth, "because their thoughts are slow, and their speech always keeps pace with their thoughts" [43] (p. 19). Children did stammer, of course, and boys were treated at Beasley's institute for their stammering as well. Some schools also employed stammering therapists to aid boys' general education.

The high-status, privileged character of the stammerer was shown by statistics - mainly through the apparent absence of underprivileged groups in stammering circles. That the stammerer was "civilized" was shown by the fluent speech of "savages". Travelers were called upon to show that no one had ever encountered speech impediments in the uncivilized world. "All travellers, who have long resided among uncultivated nations", it was stated, "maintain that they never met with any savages labouring under an impediment of speech" [27] (p. 39). This was because, according to scientists like Hunt, its 
inhabitants were not subjected to the stress and strain of civilization: their fluent speech was owed to "their freedom from mental anxieties and nervous debility, the usual concomitants of refinement and civilization" [27] (p. 39). Likewise, the lower classes did not appear to seek the help of therapists and were considered to be relatively free of the impediment. Women and the elderly were excluded for slightly different reasons. According to Hunt, no one had ever heard on old man stutter, because stammerers simply did not live very long [27] (p. 126). Women, on the other hand, were not so much thought of as uncivilized, but rather as more suited to civilization and its rhythms of speech than men. Individual cases of female stammerers occasionally surfaced, but they were thought to represent a very small percentage of stammerers. According to Richard Faulkner, women expended less energy on speaking. "We have compared subsequently the energy developed in conversing by the voice of a man and that of a woman, and have found that women are fatigued, in talking, four times less than a man" [45]. Others had already suggested that women were naturally good at speech. What made women's speech so fluent, these theories surmised, was that most of it was idle chatter anyway.

Especially toward the end of the 19th century, the socially elevated status of the stammerer became connected to the assumed quality of his (intended) discourse. Whereas "savages" could not speak of anything beyond the concrete and women did not move beyond the trivial, the (male, middle-class) stammerer's laborious speech betrayed his intelligence. The gist of the argument was that his thoughts were so complex and flowed so quickly that the mouth could not follow. According to Benjamin Beasley, founder of not only a "method" but of a whole institution for stammerers, "when thoughts come too rapidly, they cannot be spoken in time" [44] (p. 55). It was no wonder, perhaps, that this argument was furthered by a man who claimed to have been a stammerer himself. Beasley acted as the ultimate advertisement for his own method by proudly claiming an identity as a (cured) stammerer. Where other self-help manuals accorded agency to their readers and offered them a perspective on privilege on a socio-political level, Beasley's Reminiscences of a Stammerer translated this notion of privilege to the arena of the personal. Going beyond statistical realties, his performance of the stammerer's identity endowed himself - and, by extension, his readership - with the kind of rational and autonomous individuality that spoke eloquently of his status within modern society. As one observer allegedly noted after hearing Beasley lecturing at the Salisbury Church House, the self-styled therapist "was a living instance of the success of his own system" [46].

Beasley's construction of self, which he conferred upon his "pupils", was that of a thriving businessman, a man of knowledge, and the (former) sufferer of a speech impediment. He was successful, it seemed, not despite his stammer, but because of it. For Beasley himself, this was of course true in the literal sense: he had built his profession on the cure of stammering, and his reputation on his history as a fellow sufferer. But his work suggested that the exemplary modernity of his personality was typical of stammerers in general. Rather than suggesting that barristers, priests, or senators were most "prone" to stammering (as had earlier been assumed because of their exposure to the "strains" of modern life), he argued that stammerers would be particularly suited to the bar, because they were so utterly intelligent, sensitive, individual, and indeed "modern". 


\section{The Sound of Stammering}

The popular representation of stammerers in songs, at the turn of the century and up until the 20s, seems very far removed from this image of the privileged, highly intelligent modern individual [47] and [48] (pp. 73-120). Although not all songs were quite as harsh as the anonymous "The Stammerer", there was a general tendency to depict the stammerer as somewhat of a dunce $[49,50]$. In "Mum-mum-mum-Mary", the stammerer gets the girl, but only because she used to stammer as well [51]. That a woman could appear at her most attractive and intelligent by not talking at all would easily have been accepted by therapists and gentlemen-scientists of the period. Her stammer, however, would have come as a surprise to them. Mary was hardly the only stammering girl represented in song, though. A 1902 tune even had "Julie, the stuttering girl" as its main character. In it, Julie, the stammering schoolteacher, gets away with some decidedly unladylike language because of her stammer.

On a pleasure trip the Sunday school once went away

and the preparation fell to Julie,

but Julie thought the work too much, so, on the festive day

Her sister Helen went with Julie

' $t$ was Julie this and Julie that,

they kept on both'ring so

till, finally some scholar came

a trifling thing to know;

and when he said "Please tell me,

where to find out shall I go?"

Said she, "Why go to Hel-hel-Helen" (1902) [52].

What these songs show, it seems, is not that scientific knowledge failed to reach the public, or that the statistics were somehow "wrong", but rather that it did not matter in the context of popular music. Composers treated stammering as a poetic and commercial opportunity, rather than as an impediment. It is no coincidence that almost all stammering songs were romantic and/or humorous in their content. The impediment was, in that sense, not the subject of the song, but merely a rhythmic device, the means to emotionally engage the audience, or the set-up for a joke. Sometimes, it was all three. In 1894, another stammering girl, Babette, appeared as the leading lady in a very twisted-tongue-in-cheek song. The refrain went

P-p-p-p-p-p-poor B-b-b-b-b-babbette, her c-c-c-c-c-case was sad, was sad, was sad!

Her int-t-t-t-t-tent was g-g-g-g-good, but her execution, her execution was b-b-b-b-bad! (1894) [53]

The joke on the stammerer's incompetence in subjecting "execution" to "intent" seems almost cruel, yet at the same time, the song invites real empathy as well. Who would not sympathize with the girl who found herself unable to admit that she longed for "one saccharine, stolen kiss"? Or with her poor admirer Raoul, who could not make out "if her mumming meant you mustn't or you may?" 
If the stammering of women (and couples) opened up sentimental possibilities, the connection of stammering to race allowed for rhythmic license. More specifically, the halting sound of stammering allowed composers to ride on the lucrative wave of ragtime music. Most explicit in the "use" of the sound of stammering was the 1913 song Stammering Sam, in which a young black boy's stammer is presented as the "origin" of ragtime.

Then Stammering Sam sang, and the company sang "babababa! Babababe!"

Singing his stuttering song with glee and that was the very first ragtime melody (1913) [54].

The connection had been made earlier, however. In 1898, The Stammering Coon told the story of "a nigger dat-a ye used fer ter-stut-ut-te-tut-ter a ge ge, good deal we worse'n me" [55]. In fact, by the onset of the First World War, the conflation of stammering and syncopation was so strong that instrumental numbers could be entitled Stammering Rag [56]. Like the stammering girls, these stammering "coons" defied scientific knowledge: their ethnicity as well as their social class should have protected them from speech impediments. Yet there they are, imaginary creatures proudly claiming syncopated speech in order to entertain.

Of course, in many ways the "stammering coons" are images of manifold oppression: their almost clownish representation derided their ethnicity, the connection arguably degraded ragtime music as it refused to take it seriously as a style, and the depiction of their accented, lower-class speech placed them firmly at the bottom of the social ladder. Being put on show, after all, also meant being subjected to the harsh gaze of the audience, to become an object of consumption. Significantly, the songs would most likely be performed by non-stammerers for other non-stammerers (although those who did stammer could, of course, hear them as well). The stammerers in the songs were mere figments of their writer's imagination, specifically created to be "performed", "bought", and "used" to serve the purposes of entertainment and consumption. Whereas stammerers were approached as agents on the market in therapeutic manuals, popular music banked on the characteristic sound of stammering in order to "sell" stammerers, rather than selling something to them.

Yet, the performed character of stammering is what connects the therapeutic and poetic discourse as well. Like therapeutic narratives, the songs showed unequivocally that stammering was something a speaker or singer had to do in order for it to exist. The sheet music in particular fulfills a function that is eerily similar to that of the self-help manual: it incited its reader to produce specific sounds, imposing particular rhythmic patterns [48] (pp. 23-37) and [57,58]. In an ironic reversal of the therapeutic logic, it turned fluent speakers into stammerers (thus perhaps proving that speech could indeed be manipulated to a great extent). Songwriters seem to have been aware of this notion of the performance of stammering in the therapeutic context. A Stuttering Song brought out in 1885 ridiculed the belief that a stammer could be "easily" cured by speech therapy, targeting not only the stammerer himself, but also the less rigorously scientific educational approaches to the impediment.

It p-p-puts me in a f-f-flutter

to h-h-hear anyone stu-tut-tut-tutter

It's s-s-such a b-b-b-bad habit to g-g-g-get in t-t-t-t-to

It's s-s-o hard to end-d-d-dure it, s-s-s-so easy to c-c-c-cure it. 
If you w-won't take the p-pains, stop at home!

That's the b-b-best thing you can d-d-do (1895) [59].

Moreover, even though stammerers were, in a way, objects of consumption in these songs, they are quite active as characters: they pursue love, invent music, and go into war. Lower class, black, and female characters take up central roles in these sung narratives.

Finally, the stammering characters in songs remind us of the multiplicity of modernity: therapeutic or scientific documents and "gentlemen" like Benjamin Beasley make it tempting to believe that the white, middle-class, professional male was the epitome of the brave new world of business and industry. But black stammerers, or Babette and Julie, show that although many could not lay claim to conventional notions of privilege, they could nevertheless engage in explicitly modern activities and embody them. Or, more importantly, that the culture that emerged from this "modern" consumerist world was shaped by women, down-at-heel sailors, and young black boys as well. The association of stammering with privilege and individuality did, in that sense, trickle down into popular culture - although composers did not simply assimilate scientists" elitist categories. The "paper trail" they have left has contributed to the dynamics of both popular music and its market, and to the evolution of perceptions of race, gender, and disability. At issue here are not only the discursive contents of these songs, but also their physical manifestations as sheet music, phonographs, and (more recently) digitized files, some of which have been very widely spread. Geoffrey O’Hara's “K-k-k-katy”, for example, was wildly popular [9] (p. 94). If stammering songs are remembered or listened to now, it is mainly because they are such eloquent examples of revolutionary changes in the music industry and powerful reminders of racial and social segregation.

\section{The Very Model of a Modern Stammerer: Conclusion}

One could wonder if the worlds of the privileged stammerer and the imaginary one in songs coincided at all. It is hard to imagine the upright Mr. Beasley at the cabaret or music hall. The difference between the stammering songs and therapeutic work is not simply one of style or genre, either. In 1838, Martin Farquhar Tupper composed a poem entitled The Stammerer's Complaint, an exceptionally explicit example of the tradition of translating the lived experience of stammering into flowing poetry [60-62]. The speaker's stammer is imagined as

The seal of lead enstamp'd upon my lips,

The load of iron on my labouring chest,

The mocking demon that at every step

Haunts me, —and spurs me on — to burst with silence! (1838)

Tupper's poem, though already written in the first half of the 19th century, chimes perfectly with the image of the over-intelligent, over-sensitive stammerer of the bourgeois world in which he - and later many theorists, physicians, and therapists-lived. There is barely any distance between his poetic discourse and the dry, scientific phrases of his peers. Yet the equally imaginative poetry of the music hall presents a different stammerer entirely, for an entirely different audience. The distance between therapy and song, then, was not one between different theories or different modes of writing. It does not tell us much about the "spread" of scientific knowledge into popular culture. 
Much more important than the difference in discourse or content is that the therapeutic and musical trails of stammering are made of vastly different "stuff", and were present on different markets. The interaction between them and the collective memories held about stammering in the 1950s and even now are therefore likely to differ as well. Whether we consider stammering to be a disability, an impediment to communication perpetuated by both the stammerer and his audience, something to stare at, or a trait of the postmodern "stuttering cyborg" is not only guided by the current medical and socio-political understandings of speech impediments, but also by the way we imagine to "know" about stammering and its social meaning [13,63]. Stammering's material culture of the past lends itself to historical analysis and therefore allows us to gauge how medical and social attitudes toward the impediment have changed; but it also acts upon personal and emotional memories. In doing so, it underlines the multiplicity ingrained in modern notions of stammering. Not only by pointing toward the different experiences of stammerers themselves and their varying ways of relation to modernity, but also by alerting us to the different meanings the history of stammering can accrue, depending on the person looking—or listening—back.

\section{Acknowledgments}

This work was supported by the Flemish Research Council (FWO). I am grateful for the helpful comments of members of the Department of Human Ecology at the University of Alberta, where an earlier version of this text was presented.

\section{Conflicts of Interest}

The author declares no conflict of interest.

\section{References and Notes}

1. There seems to be, at least since the Enlightenment, an intuitive notion that sound is more intimate and direct than sight (and therefore that recordings bear more "life" than photographs). James Joyce's proposal of a "gramophone in every grave" in order to remember deceased family members in Ulysses refers to this phenomenon. Scholars in sound studies have noted this durable connection between the audible and emotion (versus the visible and rational) as well.

2. Erlmann, V. Reason and Resonance. A History of Modern Aurality; Zone Books: New York, NY, USA, 2010.

3. Which is not to say that digital music is devoid of materiality. In his history of the MP3, Jonathan Sterne devotes the last chapter to the question if music is "a thing". According to Sterne, "the form and matter of music remain closely bound today, especially if we consider the ways in which recordings move across formats and milieus". In that sense, my digital files are as much part of the material history of this particular archive of popular songs as their original recording.

4. Sterne, J. MP3. The Meaning of a Format; Duke University Press: Durham, NC, USA, 2012; p.186.

5. This particular form of charity was wide-spread the Netherlands and Flanders, where tin foil was known as "silver paper" (and therefore perhaps seemed to have more value). It was organized by Catholic organizations such as Genootschap der H. Kindsheid and Sint-Petrusliefdewerk. 
6. Vints, L. Kongo Made in Belgium: Beeld van een Kolonie in Film en Propaganda; Kritak: Leuven, Belgium, 1984; p. 64.

7. In fact, it is its sheer ubiquity_-And the associated capacity to "deny its own rhetoricity" - That makes ableist discourse so pervasive and therefore culturally significant. As James L. Cherney has shown, the hidden rhetoricity of ableist language can make its analysis as ideology difficult, but not impossible.

8. Cherney, J.L. The Rhetoric of Ableism. Available online: http://dsq-sds.org/article/view/1665/1606 (accessed on 26 October 2015).

9. Goldmark, D. Stuttering in American Popular Song, 1890-1930. In Sounding Off: Theorizing Disability in Music; Lerner, N., Straus, J.N., Eds.; Routledge: New York, NY, USA, 2006.

10. Sterne, J. The Audible Past. Cultural Origins of Sound Reproduction; Duke University Press: Durham, CA, USA, 2003; p. 7.

11. The Wellcome Collection, in London, holds a number of stammering-related objects, as well as patent applications for numerous "inventions" intended to cure the stammerer.

12. Joshua St. Pierre aptly defines stuttering as dialogical in nature. "Broken speech' is constructed by both a speaker and a hearer". It therefore locates itself somewhere "between" two bodies, yet it is also an "embodied act".

13. St. Pierre, J. The Construction of the Disabled Speaker. Locating Stuttering in Disability Studies. In Literature, Speech Disorders and Disability: Talking Normal; Eagle, C., Ed.; Routledge: New York, NY, USA, 2013; pp. 9-23.

14. Connor, S. Dumbstruck: A Cultural History of Ventriloquism; Oxford University Press: Oxford, UK, 2000.

15. Bloom, G. Voice in Motion, Staging Gender, Shaping Sound in Early Modern England; University of Pennsylvania Press: Philadelphia, PA, USA, 2007.

16. Merkel, C.L. Anatomie und Physiologie des Menschlichen Stimm- und Sprach-Organe (Anthropophonik); Verlag von Ambrosius Abel: Leipzig, Germany, 1857.

17. Mills, W. Voice Production in Singing and Speaking, Based on Scientific Principles; J. Curwen and Sons: London, UK, 1906.

18. Müller, J. The Physiology of the Senses, Voice, and Muscular Motion, with the Mental Faculties, Taylor; Walton and Maberly: London, UK, 1848.

19. Brackhane, F. Die Sprechmaschine Wolfgang von Kempelens-Von den Originalen bis zu den Nachbauten. Phonus 2011, 16, 49-148.

20. Exemplified by the invention, and subsequent regular use, of the laryngoscope, but also of numerous machines in visualizing the voice on paper. Perhaps most exemplary of this obsession with the visible voice were René Marage's courses on vocal physiology at the Sorbonne, in which he introduced different (mechanical, electrical and photographic) methods and means to "measure" the voice.

21. Marage, R. Petit Manuel de Physiologie de la Voix à L'usage des Chanteurs et des Orateurs; Chez l'auteur: Paris, France, 1911.

22. Rockey, D. Speech Disorder in Nineteenth Century Britain. The History of Stuttering; Croom Helm: London, UK, 1980. 
23. Hoegaerts, J. Is it a habit or is it a disease? The changing social meaning of stammering in nineteenth-century Western Europe. Terrains Trav. 2013, 23, 17-37.

24. Yearsley and Dieffenbach were competitors in the field, each claiming to have invented and initiated the operations on the frenulum to cure stammering.

25. Yearsley, J. Stammering and Other Imperfections of Speech, Treated by Surgical Operations on the Throat; Churchill: London, UK, 1841; p. 24.

26. Dieffenbach, J.H. On the Cure of Stammering by a New Operation, Addressed to the Institute of France. Prov. Med. Surg. J. 1841, 25, 402-405.

27. Hunt, J. Stammering and Stuttering, Their Nature and Treatment; Longman, Green, Longman and Roberts: London, UK, 1861.

28. Lee, E. On Stammering and Squinting, and on the Methods for Their Removal; John Churchill: London, UK, $1841 ;$ p. 37.

29. It therefore fit in with a more general interest in the importance of strong lungs and "natural" breathing at the time, with the rise of scientific interest in the lungs (possibly inspired by returning TB epidemics) and the invention of therapeutic methods such as the Alexander method.

30. Alexander, F.M. Introduction to a New Method of Respiratory Vocal Re-Education; Baillier, Tindall and Cox: London, UK, 1906.

31. Pavid, H. Traité sur la Guérison du Bégaiement et de Toutes les Défectuosités de Pronunciation; Durand: Paris, France, 1864; p. 16.

32. Yearsley, W. A Practical Self-Cure of Stammering and Stuttering; Accrington: London, UK, 1909.

33. Appelt, A. The Real Cause of Stammering and Its Permanent Cure. A Treatise on Psycho-Analytical Lines; Methuen \& Co.: London, UK, 1911; p. 132.

34. Broca, P. Du siège de la faculté du langage articulé dans l'hémisphère gauche du cerveau. Bull. Soc. Anthropol. 1865, 6, 1-18.

35. Sutro, E. Duality of Thought and Language. An Outline of Original Research; Dryden House: London, UK, 1904; p. 198.

36. Bennett, E.F.T. A Self Cure for Stammering, Stuttering and Indistinct Speech; Simpkin, Marshall, Hamilton, Kent \& Co.: London, UK, 1905.

37. The brochure was 23 pages long and sold for one cent.

38. Ueyama, T. Health in the Marketplace: Professionalism, Therapeutic Desires, and Medical Commodification in Late-Victorian London; University of Washington Press: Seattle, WA, USA, 2010.

39. Then and now, the objects connected to stammering do indeed possess a certain autonomy (or "agency"): they do not just communicate meaning to the historian as artefacts, but were valuable and meaningful per se. Their value to historians therefore lies not only in their durability (objects last longer than memories), but also in their active engagement with memory and the passage of time. "Artefacts", archeologist Andrew Jones maintains, play a role in "cultural reproduction" and can, accordingly, afford insights into historical continuity and change.

40. Harvey, K. History and Material Culture; Routledge: New York, NY, USA, 2009; pp. 4-5.

41. Jones, A. Memory and Material Culture; Cambridge University Press: Cambridge, UK, 2007; p. 3.

42. Cook, N. Beyond the Score. Music as Performance; Oxford University Press: Oxford, UK, 2013; p. 6. 
43. Klindworth, L. Stuttering and How to Cure It: A Practical and Systematical Handbook for Self-Instruction; Containing an Approved Method of Respiration and the Gymnastic of Voice and Speech; F. Bauermeister: Glasgow, UK, 1896.

44. Beasley, B. Stammering: Its Treatment; Waterlow and sons: London, UK, 1888.

45. Faulkner, R.B. The Tonsils and the Voice in Science, Surgery, Speech and Song; The Presbyterian Book Store: Pittsburgh, PA, USA, 1913.

46. Beasley, B. Reminiscences of a Stammerer; The Roxburghe Press: London, UK, 1902; p. 139.

47. Even though the audience for sheet music and self-help manuals cannot have been very different: reading and buying both would have come relatively cheap, but supposed some level of education. The period was known for a wide-spread availability (and use) of cheap sheet-music, including the rise of Tin Pan Alley in New York, echoing the performances in music halls (which also attracted both a lower and middle class audience). On the popular music "market" in the second half of the nineteenth century.

48. Russell, D. Popular Music in England 1840-1914: A Social History; Manchester University Press: Manchester, UK, 1997.

49. The song was, most likely, spread by itinerant street musicians whose "work" was generally considered not only of low musical quality, but also lacking in moral qualities. The figure of the mobile street-singer was often associated with various migrant groups who were seen as loud, intrusive foreigners. By the end of the nineteenth century, middle-class observers upheld a discourse of constant complaint about their noise. (Charles Dickens, for example, was famously annoyed by street musicians.)

50. Kyprianides, C. Musical Miscellany in Charles Dickens's Journals, 1850-70. Vic. Period. Rev. 2014, 47, 397-431.

51. Murphy, C.W. Mum-mum-mum-mary; Francis, Day and Hunter: London, UK, 1909.

52. Stonehill, M. Julie the Stuttering Girl; T.B. Harms \& Co.: New York, NY, USA, 1902.

53. Goodwin, J.C.; Jakobowski, E. Babbette! (Stuttering Song); T.B. Harms \& Co.: New York, NY, USA, 1894.

54. Weston, R.P.; Barnes, F.; Elton, F. Stammering Sam; Francis, Day, and Hunter: London, UK, 1913.

55. Leavitt, H.Y. The Stuttering Coon; M. Witmark \& Sons: New York, NY, USA, 1898.

56. Gillies, J.M. The Stammering Rag; Charles Sheard \& Co.: London, UK, 1913.

57. Although the relation between a musical score and the sounding "piece" resulting from it is hardly straight-forward (and involves the creative intervention of a musician), it is generally understood that the score "pre-scribes" musical practice, and that the ability to read music equates with the ability to "convert music notation into sound". This is particularly true for late nineteenth century music, a period in which composers' authority was at its height, and when music educators were developing numerous systems to teach singers of all classes to "read" music easily and correctly.

58. McClung, A. Sight-Singing Systems: Current Practice and Survey of All-State Choristers. Appl. Res. Music Educ. 2001, 20, 3-8.

59. Harraden, H. A Stuttering Song; J.B. Cramer \& Co: London, UK, 1895.

60. Tupper is by no means the only author to mobilize his/a speech disorder to produce literature: there's a long and rich tradition of literary renditions of dysfluency in general, and poetic articulation of stammering in particular. 
61. Tupper, M. The Stammerer's Complaint. In Geraldine, A Sequel to Coleridge's Christabel: With Other Poems; Rickerby: London, UK, 1838; pp. 119-123.

62. Eagle, C. Dysfluencies: On Speech Disorders in Modern Literature; Bloomsbury: London, UK, 2013.

63. St. Pierre, J. Cripping Communication: Speech, Disability, and Exclusion in Liberal Humanist and Posthumanist Discourse. Commun. Theory 2015, 3, 1-19.

(C) 2015 by the authors; licensee MDPI, Basel, Switzerland. This article is an open access article distributed under the terms and conditions of the Creative Commons Attribution license (http://creativecommons.org/licenses/by/4.0/). 